Revista de Educação e Pesquisa em Contabilidade

Journal of Education and Research in Accounting

Revista de Educación e Investigatión en Contabilidad
REPeC, Brasília, v. 6, n. 2, art. 6, p. 204-220, abr.jun. 2012 Disponível online em www.repec.org.br

ISSN 1981-8610

\title{
Um Estudo sobre a Interação entre a Pesquisa Científica e a Prática Profissional Contábil
}

\author{
Ana Paula Batista da Silva \\ Mestre em Ciências Contábeis - Unisinos \\ Professora Assistente da Universidade do Vale do Rio dos Sinos - Unisinos e da Universidade de Santa Cruz do Sul - UNISC \\ Endereço: Av. Unisinos, 950, Bairro Cristo Rei-CEP 93.022-000, São Leopoldo-RS \\ E-mail: ana.sho@hotmail.com
}

\section{Ernani Ott}

Doutor em Ciências Contábeis

Professor Titular da Universidade do Vale do Rio dos Sinos - Unisinos

Endereço: Av. Unisinos, 950, Bairro Cristo Rei-CEP 93.022-000, São Leopoldo-RS

E-mail:ernani@unisinos.br

\section{Resumo}

Este estudo teve por objetivo analisar a interação da pesquisa científica com a prática da profissão contábil. Trata-se de um estudo exploratório, por se dedicar a examinar um tema pouco explorado no Brasil, com abordagem quantitativa e utilização de survey como técnica de coleta dos dados, apoiada por um instrumento de pesquisa contendo questões que abordaram aspectos como: interesse e utilização das pesquisas; estudo e desenvolvimento de temas; meios de divulgação da pesquisa; e causas da lacuna entre a pesquisa e a prática. É classificado quanto aos objetivos como descritivo, na medida em que se descreveu como se dá esta interação. Os dados foram analisados mediante a técnica estatística de análise fatorial do tipo $\mathrm{R}$, resumindo-os em fatores para a posterior análise, validados por meio dos testes Kaiser-Meyer-Olkin (KMO) e Bartlett de esferacidade. Concluiu-se que, em razão das diferentes naturezas, é natural certo distanciamento entre a pesquisa e a prática contábil. No entanto, esse pode ser minimizado, entre outros fatores, pelo grande interesse dos profissionais em conhecer e aplicar os resultados de pesquisas na prática, e, ainda, pela confirmação de que os temas mais pesquisados na área contábil correspondem aos temas de maior interesse na opinião dos profissionais contábeis. Tais resultados sugerem que a interação e a comunicação entre a academia e os profissionais contabilistas devam merecer maior atenção visando torná-las mais eficazes.

Palavras-chave: Pesquisa Científica; Prática Contábil; Profissional Contábil.

Editado em Português, Inglês e Espanhol. Versão original em Português.

Recebido em 08/01/11. Pedido de Revisão em 02/04/11. Aceito em 31/10/2011 por Valcemiro Nossa (Editor). Publicado em 28/06/12. Organização responsável pelo periódico: CFC/FBC/ABRACICON.

Copyright (C) 2012 REPEC. Todos os direitos, até mesmo de tradução, são reservados. É permitido citar parte de artigos sem autorização prévia, desde que seja identificada a fonte. 


\section{INTRODUÇÃO}

O desenvolvimento e a divulgação da pesquisa científica em Ciências Contábeis no Brasil são relativamente recentes, porém vem sendo incrementadas nos últimos anos, principalmente, em decorrência do aumento no número de programas de mestrado e doutorado, periódicos e congressos científicos da área.

A interação entre a produção de conhecimentos na área de contabilidade e a absorção e aplicação destes conhecimentos pelos profissionais assume relevância, na medida em que há um sentimento de que diversas questões enfrentadas no dia a dia por contadores podem ser solucionadas a partir dos estudos realizados por pesquisadores da área contábil, o que leva a se questionar sobre a aplicabilidade das pesquisas e a sua contribuição para a prática da profissão contábil.

Conforme Moehrle et al. (2009), o impacto que as ideias coletivas da academia apresentam sobre a eficiência e a eficácia da prática da profissão tem sido pouco reconhecido, porém, se aumentar a consciência sobre os efeitos da pesquisa científica em contabilidade em relação à prática da profisssão, este impacto pode ser mais amplamente reconhecido, podendo contribuir para que os empresários se sintam mais dispostos a investir na formação pós-graduada.

A maior comunicação entre a prática e a pesquisa científica possibilitará o atendimento de necessidades dos profissionais, além de tornar a pesquisa mais aplicada e, desta forma, mais interessante para os usuários, o que poderá servir de incentivo para investimentos e parcerias entre empresas e academia (LEISENRING; JOHNSON, 1994; DIAMOND, 2005; MOEHRLE et al., 2009).

Os elementos dispostos nos parágrafos precedentes motivam o desenvolvimento desta pesquisa, que se propõe a responder à seguinte questão: Como os profissionais da área contábil avaliam a interação da pesquisa científica com a prática da profissão? Para tal, este tema é examinado a partir do ponto de vista de contabilistas do Rio Grande do Sul, não sendo consideradas nesse estudo as características metodológicas e a qualidade da produção científica da área, assim como não é objetivo do estudo analisar as referências bibliográficas, nem os padrões de produtividade dos pesquisadores. O que se pretende é analisar a interação que existe entre a pesquisa acadêmica e a prática da contabilidade no campo profissional, sob a ótica de contabilistas do Rio Grande do Sul.

Espera-se que os resultados desta pesquisa possam contribuir para o debate acerca da importância da pesquisa científica na área contábil e para a configuração do desenho de linhas de pesquisa dos programas de pós-graduação, visando atingir um melhor alinhamento da pesquisa com as necessidades demandadas na prática da profíssão.

\section{REFERENCIAL TEÓRICO}

\subsection{Pesquisa contábil em âmbito internacional}

A discussão em relação à aplicação prática dos resultados das pesquisas científicas e o interesse dos profissionais em conhecer e utilizar esses resultados têm servido de temas de reflexão para diversos autores em âmbito internacional, como Edwards e Emanuel (1990), Leisenring e Johnson (1994), para quem as pesquisas tornaram-se mais complexas em razão da utilização cada vez maior de métodos matemáticos e estatísticos sofisticados, sendo considerados, por vezes, irrelevantes aos olhos dos profissionais. Os autores advertem, no entanto, que se espera que os praticantes da contabilidade apresentem um nível de conhecimento técnico desejável para que estejam aptos a compreender os resultados das pesquisas. Questões estruturais do processo de ensino na graduação dos cursos de Ciências Contábeis certamente influenciam o nível de aproximação dos alunos à pesquisa científica.

Diamond (2005), nessa mesma linha de raciocínio questiona: “(a) os profissionais da Contabilidade são receptivos à pesquisa acadêmica?; e (b) os resultados da pesquisa mudam a prática?". Mitchell (2002), por seu turno, menciona que as necessidades de informações das empresas são cada vez mais específicas, em função da maior concorrência, competição e demais consequências da globalização. Visando atender às necessidades dos profissionais da Contabilidade, a pesquisa contábil, portanto, deveria se tornar mais atrativa para eles. Não se trata de exigir que esta atenda exclusivamente às necessidades 
encontradas na prática, porém pesquisar e publicar somente para outros pesquisadores é pouco benéfico para a disciplina como um todo, tanto no sentido acadêmico, quanto na prática da profissão.

Mitchell (2002) faz referência de que a pesquisa em Contabilidade tem tido pouca relevância para a prática, corroborando resultados de estudos de autores como Edwards e Emmanuel (1990), que abordam a questão do distanciamento entre a pesquisa e a aplicação prática dos seus resultados, assim como em relação aos pontos de vista de pesquisadores e profissionais da Contabilidade, no que se refere aos tópicos a serem pesquisados. Isso leva a que Mitchell (2002) considere que, nas últimas décadas, tem ocorrido um divórcio entre a pesquisa e a prática na contabilidade, ainda que no âmbito internacional esteja aumentando o número de pesquisas, assim como de pesquisadores na área.

Collis e Hussey (2006) entendem que o atendimento das necessidades dos praticantes da Contabilidade torna a pesquisa aplicada mais interessante, já que é utilizada para aplicar suas descobertas a um problema específico existente. Os autores, porém, chamam a atenção para o fato de que a realização de pesquisa básica é fundamental para a construção de conhecimentos, na medida em que é conduzida para aumentar o entendimento sobre questões gerais, sem ênfase em sua aplicação imediata. Propugnam que haja um equilíbrio entre a produção de pesquisas aplicadas e pesquisas básicas, pois assim a produção de conhecimentos não seria prejudicada e, ao mesmo tempo, as necessidades dos profissionais da Contabilidade ganhariam maior relevância no mundo acadêmico.

Luft e Shields (2002) mencionam que a pesquisa em Contabilidade será mais interessante e útil se abordar menos a identidade disciplinar e, sim, usar uma variedade de estruturas teóricas das ciências sociais para fornecer explanações mais completas da prática da Contabilidade. Entendem como sendo necessária a abordagem prática dos problemas enfrentados por profissionais da Contabilidade como objeto de estudos da área contábil, mas que também contemplem teorias referentes às ciências sociais, onde poderão existir análises sob outras perspectivas, aquelas que contemplam as ciências sociais.

A informação contábil deve ser elaborada de forma que seja compreensível aos usuários da informação, que compreendem, entre outros, os funcionários das entidades, os acionistas, os administradores e os gerentes (THEOPHILO; IUDÍCIBUS, 2005). Segundo Mitchell (2002), as principais rotas de saída das pesquisas apontadas são: (a) outros pesquisadores; (b) diretamente para profissionais contábeis, o que geralmente não ocorre; e (c) indiretamente aos profissionais, por meio do processo educacional. Ao indagarem o porquê dessa realidade em relação à pesquisa e prática contábil, Edwards e Emmanuel (1990) apontam para a questão relacionada ao foco preferencial dos pesquisadores, geralmente adversos às questões técnicas, as quais provavelmente representam os interesses mais imediatos dos profissionais.

Leisenring e Johnson (1994) mencionam o fato de que os meios de comunicação comuns no meio empresarial, como os periódicos, costumam priorizar o rigor metodológico e pouco se preocupam com a aplicação e utilização prática das pesquisas. Estudos que apresentam soluções para problemas encontrados na prática geralmente são considerados pouco interessantes na academia, pois esses temas, na maioria das vezes, já foram bastante estudados e suas metodologias já estão perfeitamente entendidas na academia. Mas quando ocorre a aplicação destas metodologias na prática, muitas vezes são encontrados diversos problemas que dificultam o seu desenvolvimento.

Donovan (2005) sugere a interação de pesquisadores e profissionais da Contabilidade na realização de projetos de estudos e publicações de artigos, para o estudo de temas interessantes para os profissionais da Contabilidade, sendo que as pesquisas poderiam ser aplicadas diretamente para a solução dos problemas encontrados na prática. O profissional da Contabilidade apresentaria seus problemas "reais" no que se refere a assuntos contábeis, e o pesquisador poderia auxiliar na sua solução. Esta seria uma parceria que poderia beneficiar pesquisadores e profissionais praticantes da Contabilidade.

\subsection{Pesquisa contábil no Brasil}

Ribeiro Filho, Lopes e Pederneiras (2004), ao analisarem a tradição, quantidade e disponibilidade de grupos e centros de pesquisa contábil no Brasil, constatam que a pesquisa em Contabilidade é um fenômeno muito recente. Theóphilo e Iudícibus (2005, p.1) argumentam que "embora ainda em pequeno 
número, os estudos que focam a produção científica em Contabilidade no Brasil têm sido mais frequentes nos últimos anos."

A implantação dos primeiros programas stricto sensu em Contabilidade no Brasil ocorreu nos anos 1970. O pioneiro foi o Programa de Mestrado da Faculdade de Economia, Administração e Contabilidade da Universidade de São Paulo-FEA/USP, em 1970. Em 1978, foi implantado o Programa de Doutorado em Ciências Contábeis na FEA/USP, pioneiro e único durante quase trinta anos. Também, em 1978, foi implantado o Programa de Estudos Pós-Graduados em Ciências Contábeis da Pontifícia Universidade Católica de São Paulo, fortemente apoiado por professores da FEA/USP. Ainda na mesma década foi criado o Programa de Mestrado em Ciências Contábeis da Fundação Getúlio Vargas, no Rio de Janeiro, que em 1991 foi reestruturado e transferido para a Universidade Estadual do Rio de Janeiro (CHIROTTO et al., 2007).

$\mathrm{Na}$ atualidade são computados dezoito programas de Mestrado em Ciências Contábeis, tanto acadêmicos como profissionais. Desse total, metade foi criada nos últimos cinco anos o que, ainda que timidamente, representa uma evolução na quantidade de pesquisas realizadas nesta área (ANPCONT, 2009). $\mathrm{O}$ aumento no número de programas de mestrado e doutorado resultou no incremento das pesquisas realizadas na área das Ciências Contábeis. Os resultados desses estudos são apresentados aos interessados em congressos e por meio de publicações em periódicos científicos. É certo que, quanto mais desenvolvidos, os grupos e os centros de pesquisas existentes na área contábil, mais estes, poderão contribuir para a construção e o desenvolvimento de teorias e o exercício da profissão. Porém, é preciso lembrar que o fato de a pesquisa contábil no Brasil estar em um processo de amadurecimento não impede que esta seja utilizada na prática por profissionais da Contabilidade.

No que se refere à classificação das áreas temáticas pesquisadas, alguns estudos têm sido realizados no Brasil envolvendo bases de dados diferentes (periódicos e congressos da área contábil), o que contribui para a maior abrangência dos veículos de divulgação da pesquisa contábil existente no País. No quadro 1, são apresentados estudos que apresentam os temas mais pesquisados em Ciências Contábeis:

\begin{tabular}{|c|c|}
\hline $\begin{array}{l}\text { a) Riccio, } \\
\text { Sakata, } \\
\text { Carastan } \\
(2004)\end{array}$ & $\begin{array}{l}\text { Constatam uma tendência para estudos em contabilidade gerencial, contabilidade financeira e auditoria. } \\
\text { Examinaram } 365 \text { textos acadêmicos de contabilidade produzidos em universidades brasileiras entre } \\
1962 \text { e } 1999 \text {, incluindo dissertações de mestrado e teses de doutorado geradas em programas oficiais de } \\
\text { pós graduação "stritu sensu" em contabilidade. A contabilidade financeira apresenta uma concentração } \\
\text { de produções entre } 1985 \text { e 1990, e uma significativa diminuição entre } 1991 \text { e 1999. Da mesma forma, } \\
\text { as pesquisas em contabilidade gerencial apresentam-se em maior quantidade até 1991, e desde então há } \\
\text { uma tendência de redução. }\end{array}$ \\
\hline $\begin{array}{l}\text { b) Oliveira } \\
\text { (2002) }\end{array}$ & $\begin{array}{l}\text { Analisou os periódicos brasileiros da área de contabilidade apresentando os temas com maior influência } \\
\text { de artigos, na seguinte ordem: } 1^{\circ} \text { Contabilidade Gerencial; } 2^{\circ} \text { Contabilidade financeira; } 3^{\circ} \text { Teoria da } \\
\text { Contabilidade; } 4^{\circ} \text { Educação e Pesquisa Contábil; } 5^{\circ} \text { Contabilidade de Custos; } 6^{\circ} \text { Exercício Profissional; } \\
7^{\circ} \text { Contabilidade Pública; } 8^{\circ} \text { Contabilidade Internacional, sendo que os demais temas apresentaram um } \\
\text { percentual inexpressivo. }\end{array}$ \\
\hline $\begin{array}{l}\text { c) Cardoso, } \\
\text { Mendonça } \\
\text { Neto, Riccio e } \\
\text { Sakata (2004) }\end{array}$ & $\begin{array}{l}\text { São examinadas publicações em seis revistas internacionais que estavam classificadas com conceito "A" } \\
\text { pela Capes, para identificar os temas mais pesquisados entre } 1999 \text { e } 2003 \text {. Os temas mais pesquisados são } \\
\text { a) Contabilidade Gerencial e Contabilidade de Custos que juntas representam 53,3\% da amostra analisada; } \\
\text { b) Contabilidade de Mercado de Capitais ou Contabilidade Financeira, que representa 6,7\% do total da } \\
\text { amostra; e, c) Contabilidade Pública com } 8,3 \% \text { do total concentrado em duas das seis revistas analisadas. }\end{array}$ \\
\hline $\begin{array}{l}\text { d) Coelho e } \\
\text { Silva (2007) }\end{array}$ & $\begin{array}{l}\text { Apresentam um estudo em que são examinadas as publicações da área de Ciências Contábeis no } \\
\text { Encontro Nacional de Pós Graduação e Pesquisa em Administração (EnANPAD) no período de } 2001 \\
\text { até } 2006 \text { somando um total de } 336 \text { artigos. O estudo revela que ao longo dos anos os números de artigos } \\
\text { que tratam do tema Contabilidade Gerencial não param de aumentar, ao passo que o número de artigos } \\
\text { que tratam do tema Contabilidade para Usuários Externos, apresenta uma redução nos últimos três anos. }\end{array}$ \\
\hline
\end{tabular}

\section{Quadro 1: Estudos sobre os Temas mais Pesquisados em Contabilidade}

Fonte: Elaborado com base em Riccio, Sakata e Carastan (2004); Oliveira (2002); Cardoso, Mendonça Neto, Riccio e Sakata (2004) e Coelho e Silva (2007). 
Cabe mencionar que, a partir de 2009, a área de Ciências Contábeis ganhou nova divisão no Encontro Anual da Associação Nacional de Programas de Pós-Graduação e Pesquisa em Administração (EnANPAD). Foram criadas novas áreas temáticas, totalizando sete, que compreendem: Contabilidade e Governança Corporativa; Contabilidade e Responsabilidade Socioambiental; Contabilidade Financeira; Contabilidade Governamental e Terceiro setor; Contabilidade Internacional; Controladoria e Contabilidade Gerencial; e Temas Livres.

\subsection{Publicações em Congressos}

Fez-se um levantamento considerando como unidades de significado os títulos, os resumos e as palavras-chave dos artigos constantes nos anais de 2008 do Congresso de Controladoria e Contabilidade da USP, EnANPAD (área de Ciências Contábeis) e Congresso da Associação Nacional de Programas de Pós-Graduação em Ciências Contábeis - ANPCONT, todos classificados com conceito "A" pela CAPES, visando identificar os temas com maior número de artigos aprovados nos respectivos eventos. Os temas classificados especificamente na área de finanças não foram considerados no levantamento, pois possuem uma área temática própria. O mesmo ocorre em relação aos temas específicos da área de educação e pesquisa em Contabilidade (nos congressos em que estes também possuem área temática específica).

$\mathrm{Na}$ Tabela 1, estão apresentados os temas de maior destaque nos três eventos (área de Ciências Contábeis) no ano de 2008.

Tabela 1: Resumo dos Temas mais pesquisados em Ciências Contábeis

\begin{tabular}{|c|c|c|c|c|}
\hline Temas mais estudados & USP & ANPCONT & ANPAD & TOTAL \\
\hline Evidenciação Contábil & 9 & 2 & 7 & 18 \\
\hline Avaliação de desempenho & 8 & - & 6 & 14 \\
\hline Analise Contábil/Econômico-Financeira & - & 2 & 10 & 12 \\
\hline Contabilidade Internacional & 7 & - & - & 7 \\
\hline Gerenciamento de Resultados & - & 3 & 5 & 8 \\
\hline Gestão sócio-ambiental/desempenho financeiro & - & 2 & - & 2 \\
\hline Sistema ERP & - & 2 & - & 2 \\
\hline Outros & 25 & 24 & 39 & 88 \\
\hline Total & 49 & 35 & 67 & 151 \\
\hline
\end{tabular}

Fonte: Anais dos Congressos USP, ANPCONT e ANPAD (2008).

Os temas mais pesquisados nos três eventos foram: (a) Evidenciação Contábil, somando 18 artigos; (b) Avaliação de Desempenho, com 14 artigos; e (c) Análise contábil econômico-financeira, somando 12 artigos. Os temas Gerenciamento de Resultados e Contabilidade Internacional também podem ser destacados.

Por meio de uma pesquisa bibliográfica e documental, utilizando a técnica de análise de conteúdo, Oliveira (2002) classificou os assuntos pesquisados por área temática, dividindo-os em Macrotemas. Considerando a classificação dos temas apresentada por Oliveira (2002), chama a atenção a centralização dos estudos no Macrotema “Contabilidade Gerencial”, que engloba os temas: Análise de Custos, Orçamento Empresarial, Gestão Estratégica de Custos, Sistemas de Informações Gerenciais, Administração Financeira, Preço de Transferência, Avaliação de Desempenho, Padrões, Métodos Quantitativos Aplicados à Contabilidade, Custo de Oportunidade, Análise das Demonstrações Contábeis, Fixação do Preço de Venda e Controladoria.

Além da Contabilidade Gerencial, destacavam-se temas como: a) Contabilidade Financeira (abordando assuntos como evidenciação contábil, normas contábeis e fiscais, etc.); b) Teoria da Contabilidade (em que são estudados tópicos como aspectos teóricos, conceituais e doutrinários sobre contabilidade, etc.); e c) Contabilidade Internacional (abordando assuntos como harmonização das normas e princípios, globalização da economia, etc.). 


\subsection{Canais de Comunicação entre Pesquisadores e Profissionais da Contabilidade}

A disseminação de pesquisas científicas realizadas na área contábil é fator fundamental para possibilitar a sua utilização, seja na prática da profissão, na área educacional, ou mesmo por outros pesquisadores. Alguns dos meios existentes de divulgação das pesquisas científicas correspondem aos periódicos científicos eletrônicos e impressos, congressos, dissertações, teses, livros, etc. Os periódicos científicos (tanto eletrônicos, quanto impressos), pelo fato de apresentarem uma sistematização onde são organizados e selecionados os assuntos, assim como a qualidade do material publicado, cumprem um papel relevante entre os canais de comunicação entre a pesquisa e a prática contábil.

Os periódicos científicos geralmente apresentam o que de mais recente vem sendo pesquisado, divulgando resultados de estudos apresentados nos eventos científicos existentes da área contábil. No entanto, mesmo sendo um meio de fácil acesso, já que são veiculados em sites ou enviados diretamente aos interessados, estes podem não estar sendo utilizados pelos profissionais da Contabilidade, seja em função de possível dificuldade de entendimento dos resultados apresentados; pelo fato de não haver, aos olhos dos profissionais, a possibilidade clara de aplicação prática desses resultados; ou ainda pelo desconhecimento destes em relação às publicações científicas.

No estudo de Mitchell (2002), é destacada a importância de publicar pesquisas e estudos realizados diretamente aos profissionais, envolvendo assuntos de interesse dos praticantes da Contabilidade, além de utilizar os meios de comunicação comuns à área. $\mathrm{O}$ autor cita o exemplo ocorrido no Reino Unido, onde os jornais de grande circulação no mercado passaram a publicar os resultados dos estudos de pesquisadores, geralmente estudos aplicados envolvendo assuntos técnicos. Como consequência, os profissionais passaram a aplicar na prática as inovações sugeridas. No entanto, estes meios de comunicação não eram usualmente utilizados no meio acadêmico, proporcionando pouca visibilidade e popularidade para aqueles pesquisadores que publicavam nestes jornais.

Conforme Hawkes et al. (2003), os pesquisadores precisam empregar esforços para que os resultados de seus estudos sejam publicados em periódicos de uso dos profissionais da Contabilidade, aqueles de grande circulação entre os profissionais da Contabilidade, e também que seja utilizada uma linguagem que possibilite um melhor entendimento pelos profissionais. A cooperação entre profissionais e acadêmicos permitiria a ambos os grupos compreender melhor porque existe a lacuna destacada por autores anteriormente citados.

Ott (2008) assinala que a disseminação dos resultados das pesquisas é feita em eventos da área científica e em periódicos (ainda em número relativamente reduzido), e menciona que a grande massa de profissionais da Contabilidade fica à margem deste processo, já que não participam destes eventos e também não recebem os periódicos. É possível, segundo o autor, que esteja ocorrendo uma falha no processo de comunicação também aos profissionais sobre a realização dos eventos e sobre a publicação dos periódicos, salientando que esta é uma questão que pode facilmente ser solucionada.

As abordagens apresentadas indicam que os fatores que podem estar contribuindo para um maior distanciamento entre estas classes (praticantes da contabilidade e academia) podem surgir de causas diversas, mas provavelmente tanto os praticantes quanto os acadêmicos são responsáveis por esta realidade. No entanto, é preciso mencionar que existem outros fatores que não são abordados neste estudo, mas que interferem diretamente na questão da interação entre a pesquisa e a prática contábil como, por exemplo, a estrutura do ensino da Contabilidade, onde o incentivo à leitura de pesquisas científicas é ainda muito baixo.

Ao se examinar se existe a indicação de público-alvo dos congressos existentes na área contábil (Associação Nacional de Pesquisa e Pós-Graduação em Administração - EnANPAD; Associação Nacional dos Programas de Pós-Graduação em Ciências Contábeis - ANPCONT, Congresso USP de Controladoria e Contabilidade; e Congresso Brasileiro de Custos - $\mathrm{CBC}$ ), constata-se que somente no site do Congresso USP de Controladoria e Contabilidade (2009) há referência a este respeito, onde consta: "Promover o debate de ideias inovativas sobre a teoria e a prática de Controladoria e Contabilidade". Esta pode ser considerada a única menção que sugere uma aproximação entre prática e pesquisa contábil. No 
que se refere ao público participante do evento, encontra-se no site do Congresso USP de Controladoria e Contabilidade (2009) a seguinte menção: "O Congresso USP tem contado com a participação de professores, pesquisadores, profissionais e alunos de todas as regiões do país, interessados na divulgação e avaliação dos seus estudos científicos". É possível que participantes inscritos como "profissionais", em sua maioria, sejam alunos de cursos de pós-graduação, que nessa condição estejam apresentando trabalhos devidamente patrocinados pelas empresas onde atuam.

O Congresso da ANPCONT é um evento de importante significado acadêmico-científico da Associação Nacional dos Programas de Pós-Graduação em Ciências Contábeis em nível nacional. No site do Congresso (2009) consta: "Este evento proporciona a interação da comunidade acadêmica, pesquisadores, professores e estudantes, representando um meio de divulgação da produção técnico-científica na área das Ciências Contábeis". É evidenciada a intenção de aproximação entre estudos acadêmicos e aplicações em empresas, ao constar que "[...] o Congresso ANPCONT é um evento que busca estabelecer uma ligação entre estudos acadêmicos e aplicações em organizações, possibilitando aos participantes conhecer mais profundamente os diversos enfoques dos estudos nas Ciências Contábeis." No site do EnANPAD não foi encontrada qualquer informação em relação ao público alvo, nem mesmo direcionamento referente ao campo prático.

Ao especificar o interesse dos profissionais praticantes da Contabilidade em participar dos eventos da área contábil, não se espera que este fato resulte na participação efetiva destes profissionais. O que se pretende é chamar a atenção para o fato de que não é manifestada, em geral, nos sites dos eventos a intenção em contar com a presença e participação de profissionais praticantes da Contabilidade.

Dessa forma, é possível inferir que o distanciamento entre estas duas classes (pesquisadores e profissionais) da área contábil pode ser fruto, entre outros aspectos: a) da falta de informação e de meios de comunicação eficazes para ambos; b) da resistência de ambas as classes em compartilhar os canais de informações existentes, no sentido de divulgar os resultados (pesquisadores) e utilizar a informação na prática (profissionais); e c) do eventual despreparo de profissionais contábeis para compreender as pesquisas acadêmicas.

Laffin (2000) também expressa sua preocupação em relação a este tópico ao mencionar que se torna necessário promover ações para ampliar as oportunidades de divulgação das pesquisas desenvolvidas, a partir da monografia de conclusão de curso. Isso poderá tomar diferentes formas, tais como seminários, simpósios, painéis, entre outros, para que sejam divulgados os trabalhos, evidenciando-se o seu valor, contribuição e formas de incentivo à pesquisa. Mais do que refletir os procedimentos adotados na iniciação científica é necessário evidenciar, por intermédio de ações, que da pesquisa resulta a construção de conhecimentos e que estes, socializados e redimensionados, interferem na construção da cidadania.

O processo educacional poderia ser uma das rotas mais eficazes para fazer com que os resultados das pesquisas fossem utilizados na prática pelo profissional da Contabilidade. No entanto, este processo pode não ser tão proveitoso, caso o estudante demore a ingressar no mercado, pois, ao se retardar a utilização de informações a eficácia deste meio de comunicação, pode ficar comprometida, além da necessidade de um maior incentivo à leitura das pesquisas científicas. $\mathrm{O}$ ideal seria que o estudante estivesse também no mercado, atuando na área contábil no momento em que a informação chegasse, e desde a graduação tivesse contato com resultados de pesquisas científicas. Assim a aplicação destes conhecimentos poderia ser imediata.

Outro caminho para informar profissionais, estudantes e pesquisadores sobre os resultados de estudos e técnicas aplicáveis na prática contábil são os livros. No entanto, entre o processo de pesquisa, de desenvolvimento e publicação dos livros, existe um período de tempo significativo e que pode da mesma forma retardar a utilização dessas informações.

Além disso, o processo de pesquisa é dinâmico, o que enseja que resultados diversos ou técnicas diferentes ou mesmo contraditórias sobre um determinado tema possam ser apresentados em pesquisas em um curto espaço de tempo, o que exigiria um canal de comunicação entre a prática e a pesquisa que apresentasse essa característica de incorporar o dinamismo da informação. 
No entanto, independente da eficiência de cada um dos meios de divulgação da pesquisa acadêmica contábil, ao divulgar as produções aos profissionais da Contabilidade, é preciso que exista interesse destes em acessar um ou mais destes meios de comunicação.

\section{PROCEDIMENTOS METODOLÓGICOS}

\subsection{Delineamento da pesquisa}

Este estudo teve por objetivo analisar a interação da pesquisa científica com a prática da profissão contábil. No que se refere ao seu objetivo, a pesquisa se enquadra como exploratória, na medida em que não foram encontrados estudos abordando essa temática e seus resultados são descritos para entendimento dos leitores (BEUREN, 2006).

Quanto à abordagem do problema, a pesquisa classifica-se como quantitativa, já que as percepções dos respondentes foram tratadas estatisticamente para posterior análise; e o procedimento técnico utilizado foi uma survey, que corresponde a uma forma de obtenção de informações diretamente com o público-alvo. Conforme Gil (2002), o levantamento ou survey é caracterizado pela interrogação direta das pessoas cujo comportamento acerca de um problema estudado se deseja conhecer para, em seguida, mediante análise quantitativa, obter-se as conclusões possíveis.

\subsection{População e amostra}

A população do estudo foi formada por contabilistas registrados no Conselho Regional de Contabilidade do Rio Grande do Sul, tendo por base uma relação fornecida pelo Conselho, contendo 7.198 contabilistas, para os quais foram enviados os instrumentos de pesquisa, retornando devidamente respondidos 328 , os quais constituíram a amostra do estudo.

\subsection{Coleta dos dados}

O instrumento de coleta de dados foi elaborado a partir do referencial teórico, contendo um total de 38 questões abordando os seguintes aspectos: a) interesse e utilização das pesquisas; b) estudo e desenvolvimento de temas da área contábil; c) meios de divulgação da pesquisa; e, d) causas da lacuna entre a pesquisa e a prática contábil. Após, foi submetido a um processo de validação por dois pesquisadores da área e a um pré-teste, onde participaram três contadores e três pesquisadores da área contábil. Para facilitar o entendimento dos respondentes, adotou-se no questionário uma escala contínua de 0 a 10 , por corresponder a uma escala de números que os indivíduos estão acostumados a utilizar, o que facilita a resposta e oferece maior flexibilidade para o respondente. O link para acesso ao instrumento (questionário) foi encaminhado aos contadores por correio eletrônico.

\subsection{Análise dos dados}

O número de respostas obtidas permitiu a análise estatística dos dados (Análise Fatorial), o que favorece um resultado mais abrangente em relação às variáveis estudadas. As técnicas de análise fatorial podem satisfazer a dois objetivos: (a) identificação da estrutura por meio do resumo de dados - Análise Fatorial do tipo R; e/ou (b) redução dos dados - Análise Fatorial do tipo Q (análise de cluster) (HAIR JUNIOR et al., 2009). Neste estudo foi utilizada a Análise Fatorial do Tipo R.

A validação da análise fatorial do tipo $\mathrm{R}$ foi realizada por meio dos testes: (a) Kaiser-Meyer-Olkin (KMO) onde é classificada a análise dos componentes principais conforme o valor obtido por meio do teste. Se este for menor que 0,5 , a amostra é considerada inaceitável; de 0,5 a 0,6 é considerada má; de 0,6 a 0,7 é razoável; de 07 a 0,8 é média; de 0,8 a 0,9 é boa; e se for entre 0,9 e 1 é muito boa; e (b) Bartlett de esferacidade onde, segundo Pereira (2006), deve-se rejeitar a hipótese nula. Esta hipótese indica não haver correlação entre as variáveis iniciais a um determinado nível de significância.

O número de fatores considerados na análise foi definido pelo critério da raiz latente. Este método considera significativo apenas os fatores com raízes latentes maiores do que 1 (um). O critério de raiz 
latente aceita que qualquer valor componente individual deve explicar a variância de ao menos uma variável, e desta forma, mantido para a análise (HAIR JUNIOR et al., 2009).

As cumunalidades representam as estimativas de variância em que cada variável é explicada pelos fatores gerados (HAIR JUNIOR et al., 2009). As cumunalidades com valor acima de 0,50 são consideradas significativas já que este valor indica que $50 \%$ da variância existente na variável em questão é explicada estatisticamente pelos fatores gerados da matriz fatorial.

\section{ANÁLISE DOS DADOS E RESULTADOS}

Por meio da análise fatorial do tipo $\mathrm{R}$, foram identificados os fatores formados, considerando as questões utilizadas no instrumento de coleta dos dados, assim como as respostas obtidas. No teste KMO foi encontrado o fator 0,836 , que indica que a análise dos componentes principais é considerada boa. $\mathrm{O}$ resultado do teste KMO pode ser verificado na Figura 1.

\begin{tabular}{|ll|r|}
\hline KMO and Bartett's Test & \\
\multicolumn{2}{|l|}{ Kaiser - Meyer - Olkin Measure of Sampling Adequacy. } & 0,836 \\
Bartlett's Test of & Approx Chi-Square & 4789,315 \\
Sphericity & DF & 703,000 \\
& Sig. & 0,000 \\
\hline
\end{tabular}

Figura 1: Resultado do teste KMO e Bartlett para as 38 variáveis

Fonte: Dados da pesquisa com utilização de SPSS 15.0

Também foi realizado o teste de esferacidade de Bartlett, obtendo-se um resultado estatisticamente significativo, apresentando um qui-quadrado de 4789,315 com 703 graus de liberdade. Conclui-se, por meio dos dados apresentados, que a análise fatorial do tipo R pode ser realizada já que os dados são correlacionáveis e a hipótese nula é rejeitada em seu nível de significância de 0,01 .

Outro teste relevante para a análise corresponde ao scree plot. Por meio deste teste, verificou-se que os 11 fatores que explicam 63,48\% da variância inicial são representados por autovalores acima de uma unidade (1). A análise scree plot é apresentada na Figura $2 \mathrm{em}$ forma de gráfico.

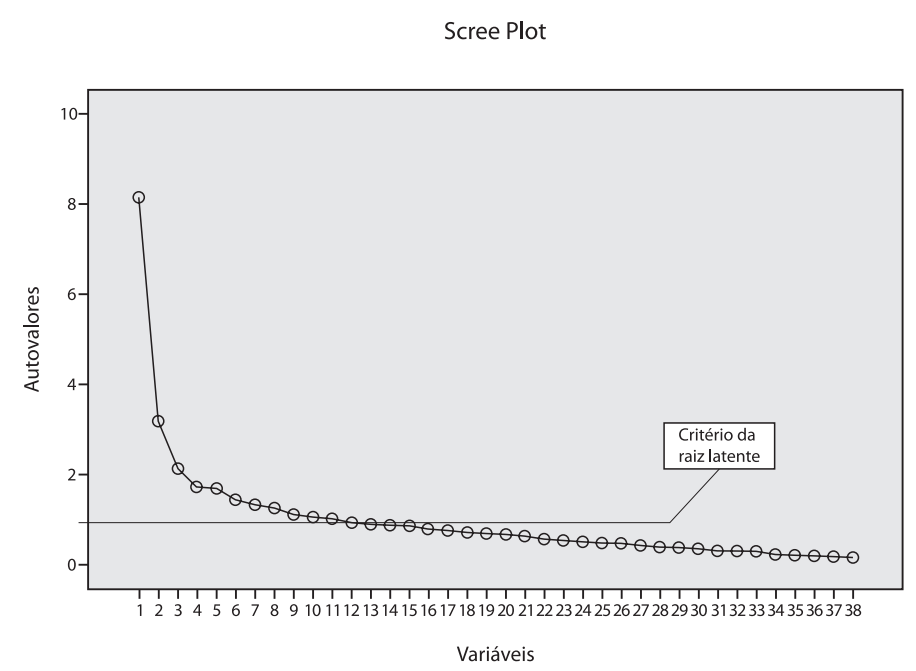

Figura 2: Critério do teste Scree Plot e raiz latente para as 38 variáveis

Fonte: Dados da pesquisa com utilização de SPSS 15.0. 
Na Figura 2, acima da linha, constam os fatores considerados para análise, somando um total de 11 fatores. Mediante a rotação da matriz original, composta pelas respostas obtidas por meio do instrumento de coleta dos dados, foi possível verificar as correlações significativas existentes. Foram analisadas as variáveis apresentadas em cada um dos 11 fatores, e após estes foram nominados segundo suas características. Desta forma, algumas questões (variáveis) utilizadas no questionário original foram desconsideradas para a análise já que apresentaram pouca relevância na análise dos dados.

A verificação das correlações foi realizada seguindo as orientações de Hair Junior et al. (2009, p.107), onde se deve primeiramente analisar a primeira variável, no primeiro fator, e mover-se horizontalmente da esquerda para a direita, procurando o valor mais alto para aquela variável em qualquer fator e seguir essa mesma lógica para as demais variáveis. Após, deve-se observar cada fator. Iniciando pelo primeiro fator, na primeira linha, analisa-se qual variável apresenta maior correlação seguindo na vertical de cima para baixo.

Cinco dos fatores apontados pela aplicação da técnica não apresentaram valores significativos (acima de 0,5), sendo estes os fatores 5, 6, 9, 10 e 11. Além disso, as variáveis: Q1, Q2, Q6, Q7, Q9, Q14, Q15, Q18, Q19, Q20, Q24, Q25, Q27, Q28, Q30, Q31 e Q32 não apresentaram alta correlação com nenhum dos 11 fatores. Sendo assim, estas variáveis foram desconsideradas para a análise.

Como já mencionado, as variáveis que não apresentaram alta correlação com nenhum dos fatores foram eliminadas. No Quadro 2, é possível verificar cada um dos fatores com as variáveis que apresentaram alta correlação, e a respectiva questão que estas representam na análise. Cabe mencionar que os fatores 5, 6, 9, 10 e 11 não apresentaram correlações significativas com nenhuma das variáveis e, portanto, não estão incluídos no Quadro 2.

\begin{tabular}{|l|l|}
\hline $\begin{array}{l}\text { 1 - Comunicação } \\
\text { com a pesquisa }\end{array}$ & $\begin{array}{l}\text { Q3 - Caso seja formado, qual seu nível de formação; Q8 - Leio com frequência artigos } \\
\text { publicados em periódicos científicos de contabilidade; Q 12 - Converso com pesquisadores } \\
\text { da área de contabilidade pelo menos uma vez por ano; Q 13 - Tenho participado } \\
\text { intensamente dos congressos da área contábil; Q 16 - Os temas a seguir relacionados são } \\
\text { aqueles cujos resultados das pesquisas eu mais utilizo: Contabilidade Gerencial; Q 17 - } \\
\text { Contabilidade e Mercado de Capitais; Q 21 Contabilidade Social e Ambiental; Q 26 - Das } \\
\text { modificações ocorridas na área contábil, que tomei conhecimento, foram através dos } \\
\text { seguintes meios: Mestrado; Q 29 - Congressos; Q 34 Periódicos impressos; Q 35 - Tenho } \\
\text { pleno conhecimento que estes congressos ocorrem anualmente: Anpad; Q 36 - Anpcont; Q } \\
\text { 37 - Congresso Brasileiro de Custos; Q 38 - Anpec. }\end{array}$ \\
\hline $\begin{array}{l}\text { 2 - Interesse e Aplicação: } \\
\text { Contabilidade Tributária }\end{array}$ & $\begin{array}{l}\text { Q 11 - Aplico, frequentemente, os resultados das pesquisas contábeis publicadas em } \\
\text { periódicos científicos; Q 22 - Os temas a seguir relacionados são aqueles cujos resultados } \\
\text { das pesquisas eu mais utilizo: Contabilidade Tributária. }\end{array}$ \\
\hline 3 - Profissional Graduado & $\begin{array}{l}\text { Q 5 - Atuo em (escritório, empresa, consultoria) Q 23 - Das modificações ocorridas na área } \\
\text { contábil, que tomei conhecimento, foram atraves dos seguintes meios: graduação. }\end{array}$ \\
\hline $\begin{array}{l}4 \text { - Dificuldade } \\
\text { de Compreensão }\end{array}$ & $\begin{array}{l}\text { Q 10 - Os artigos científicos, publicados em periódicos da área contábil, são de difícil } \\
\text { compreensão. }\end{array}$ \\
\hline $\begin{array}{l}\text { 7 - Tempo } \\
\text { de Formação }\end{array}$ & Q 4 - Formado a: (menos de 5 anos; entre 5 e 10 anos; entre 0 e 5 anos; mais de 15 anos) \\
\hline 8 - Legislação & $\begin{array}{l}\text { Q 33 - Das modificações ocorridas na área contábil, que tomei conhecimento, foram através } \\
\text { dos seguintes meios: Legislação }\end{array}$ \\
\hline
\end{tabular}

\section{Quadro 2: Composição dos Fatores}

Fonte: Resultados da Matriz Rotacionada. 
A partir da interpretação dos resultados apresentados no Quadro 2, foi possível nominar os fatores de acordo com as características de cada um, observando, para tanto, cada uma das questões que os compõem e, principalmente, aquela que apresentou a maior correlação.

Para melhor entendimento da composição de cada um dos fatores, assim como da definição das nomenclaturas, a seguir são apresentados individualmente os fatores, as variáveis que os compõem, os nomes de cada um dos fatores e a justificativa para a sua definição.

a) FATOR 1 - “Comunicação com a Pesquisa" - A escolha pela nomenclatura justifica-se em razão do elevado número de elementos que verificam o nível de proximidade com a pesquisa, como, por exemplo: nível de formação: pós-graduação, leitura frequente de artigos publicados em periódicos, contato com pesquisadores, etc.

b) FATOR 2 - "Interesse e aplicação: Contabilidade Tributária" - A opção pelo nome mencionado deu-se em razão do destaque para a variável contabilidade tributária, além da variável que verifica o nível da aplicação frequente dos resultados das pesquisas publicadas nos periódicos.

c) FATOR 3 - "Profissional Graduado" - O nome "Profissional Graduado" foi definido com base nas variáveis que indicam o nível de concordância/discordância de que a graduação é o principal meio de atualização em relação aos assuntos contábeis, além de verificar o setor de atuação profissional na área contábil.

d) FATOR 4 - "Grau de Compreensão" - O fator 4 apresenta somente uma variável significativa. Neste fator percebe-se que a verificação do nível da dificuldade de compreensão é o seu principal elemento, justificando a definição do seu nome.

e) FATOR 7 - “Tempo de Formação" - Este fator também apresenta somente uma variável significativa, tempo de formação, o que justifica a escolha do nome.

f) FATOR 8 - "Legislação" - No fator 8 a única variável significativa é a que verifica o nível de utilização da legislação como o meio mais empregado para atualização dos assuntos contábeis, justificando a adoção do seu nome.

\subsection{Interpretação dos Resultados da Análise Fatorial}

A seguir são apresentadas as interpretações dos resultados da análise fatorial, com os percentuais de posicionamentos para cada uma das variáveis que formam os fatores, assim como as reflexões realizadas com base na análise dos dados.

a) ANÁLISE DOS DADOS DO FATOR 1 - "Comunicação com a Pesquisa" - A primeira informação obtida por meio da análise dos dados do fator 1, indica a existência de uma diversidade no nível de formação dos respondentes, onde $4 \%$ são técnicos em contabilidade, $31 \%$ são graduados em Ciências Contábeis, $31 \%$ possuem MBA ou Especialização e 23\% dos respondentes possuem mestrado ou doutorado. Estes dados revelam que $64 \%$ dos respondentes afirmam possuir pós-graduação, o que pode sugerir um contato maior com as pesquisas.

$\mathrm{Na}$ Tabela 2 constam os percentuais de posicionamentos para cada valor de 0 a 10 , considerando as variáveis que formam o fator 1 . 
Tabela 2: Percentuais de Posicionamentos para o Fator 1

\begin{tabular}{|c|c|c|c|c|c|c|c|c|c|c|c|c|c|}
\hline \multirow[t]{2}{*}{ Variáveis } & \multicolumn{13}{|c|}{ \% de Respostas } \\
\hline & \multicolumn{2}{|c|}{ Tec. } & \multicolumn{2}{|c|}{ Cont. } & \multicolumn{2}{|c|}{$\begin{array}{l}\text { Esp./ } \\
\text { MBA }\end{array}$} & \multicolumn{2}{|c|}{$\begin{array}{l}\text { Mes./ } \\
\text { Dout. }\end{array}$} & & & & & \\
\hline $\begin{array}{l}\text { Q } 3 \text { - Caso seja formado, qual seu nível de } \\
\text { formacão: }\end{array}$ & \multicolumn{2}{|c|}{$4 \%$} & \multicolumn{2}{|c|}{$31 \%$} & \multicolumn{2}{|c|}{$41 \%$} & \multicolumn{2}{|c|}{$23 \%$} & & & & & \\
\hline & $\mathbf{0}$ & 1 & 2 & 3 & 4 & 5 & 6 & 7 & 8 & 9 & 10 & de 0 a 4 & de 6 a 10 \\
\hline $\begin{array}{l}\text { Q } 8 \text { - Leio com frequeência artigos } \\
\text { publicados em periódicos científicos de } \\
\text { contabilidade }\end{array}$ & 9 & 1 & 5 & 4 & 3 & 15 & 4 & 12 & 21 & 7 & 19 & 22 & 63 \\
\hline $\begin{array}{l}\text { Q } 12 \text { - Converso com pesquisadores da } \\
\text { área de contabilidade pelo menos uma vez } \\
\text { por ano; }\end{array}$ & 31 & 6 & 6 & 3 & 3 & 8 & 2 & 4 & 6 & 5 & 26 & 49 & 43 \\
\hline $\begin{array}{l}\text { Q } 13 \text { - Tenho participado intensamente dos } \\
\text { congressos da área contábil; }\end{array}$ & 38 & 6 & 7 & 7 & 3 & 10 & 3 & 7 & 5 & 4 & 10 & 61 & 29 \\
\hline $\begin{array}{l}\text { Q } 16 \text { - Os temas a seguir relacionados são } \\
\text { aqueles cujos resultados das pesquisas eu } \\
\text { mais utilizo: Contabilidade Gerencial }\end{array}$ & 21 & 2 & 6 & 6 & 2 & 15 & 3 & 10 & 17 & 5 & 13 & 37 & 48 \\
\hline $\begin{array}{l}\text { Q } 17 \text { - Os temas a seguir relacionados são } \\
\text { aqueles cujos resultados das pesquisas eu } \\
\text { mais utilizo: Contabilidade e Mercado de } \\
\text { Capitais }\end{array}$ & 10 & 1 & 2 & 2 & 3 & 12 & 5 & 9 & 23 & 13 & 20 & 18 & 70 \\
\hline $\begin{array}{l}\text { Q } 21 \text { - Os temas a seguir relacionados são } \\
\text { aqueles cujos resultados das pesquisas } \\
\text { eu mais utilizo: Contabilidade Social e } \\
\text { Ambiental }\end{array}$ & 35 & 4 & 9 & 8 & 5 & 14 & 5 & 5 & 7 & 3 & 5 & 61 & 25 \\
\hline $\begin{array}{l}\text { Q } 26 \text { - Das modificações ocorridas na área } \\
\text { contábil, que tomei conhecimento, foram } \\
\text { através dos seguintes meios: Mestrado }\end{array}$ & 60 & 2 & 3 & 0 & 1 & 5 & 1 & 2 & 5 & 6 & 15 & 66 & 29 \\
\hline $\begin{array}{l}\text { Q } 29 \text { - Das modificações ocorridas na área } \\
\text { contábil, que tomei conhecimento, foram } \\
\text { através dos seguintes meios: Congressos }\end{array}$ & 31 & 3 & 5 & 3 & 3 & 9 & 8 & 5 & 16 & 6 & 11 & 45 & 46 \\
\hline $\begin{array}{l}\text { Q } 34 \text { - Das modificações ocorridas na área } \\
\text { contábil, que tomei conhecimento, foram } \\
\text { através dos seguintes meios: Periódicos } \\
\text { Impressos }\end{array}$ & 52 & 3 & 3 & 2 & 10 & 8 & 2 & 2 & 3 & 4 & 20 & 70 & 31 \\
\hline $\begin{array}{l}\text { Q } 35 \text { - Tenho pleno conhecimento que este } \\
\text { congresso ocorre anualmente: Anpad }\end{array}$ & 55 & 3 & 4 & 1 & 2 & 10 & 2 & 2 & 2 & 3 & 16 & 65 & 25 \\
\hline $\begin{array}{l}\text { Q } 36 \text { - Tenho pleno conhecimento que este } \\
\text { congresso ocorre anualmente: Anpcont }\end{array}$ & 50 & 2 & 4 & 2 & 2 & 8 & 2 & 2 & 5 & 3 & 20 & 60 & 32 \\
\hline $\begin{array}{l}\text { Q } 37 \text { - Tenho pleno conhecimento que este } \\
\text { congresso ocorre anualmente: Congresso } \\
\text { Brasileiro de Custos }\end{array}$ & 56 & 2 & 2 & 2 & 2 & 8 & 3 & 1 & 5 & 3 & 16 & 64 & 28 \\
\hline $\begin{array}{l}\text { Q } 38 \text { - Tenho pleno conhecimento que este } \\
\text { congresso ocorre anualmente: Anpec }\end{array}$ & 66 & 3 & 3 & 2 & 3 & 9 & 2 & 3 & 3 & 1 & 5 & 77 & 14 \\
\hline
\end{tabular}

Fonte: Dados da Pesquisa.

Por meio da análise dos resultados do fator 1 - Comunicação com a Pesquisa, verifica-se que $63 \%$ dos respondentes afirmam (entre os níveis 6 e 10) que frequentemente leem periódicos da área contábil. Além disso, as respostas para os níveis entre 6 e 10 em relação ao interesse e aplicação do tema 
“contabilidade gerencial”, corresponde a 48\%; já em relação ao tema "contabilidade e mercado de capitais", corresponde a 70\%. No entanto, em relação à utilização de "congressos" como meio para atualização dos assuntos relacionados à Contabilidade, o percentual de respostas para os níveis entre 0 e 4 corresponde a $45 \%$, enquanto que o percentual de respostas para os níveis entre 6 e 10 corresponde a 46\%. Todas as demais afirmações receberam o maior percentual de respostas entre os níveis 0 e 4, o que indica a não concordância dos respondentes.

b) ANÁLISE DOS DADOS DO FATOR 2 - "Interesse e aplicação: Contabilidade Tributária" - Os percentuais de posicionamento para as variáveis que compõem o fator 2 podem ser verificados na Tabela 3.

Tabela 3: Percentuais de Posicionamentos para o Fator 2

\begin{tabular}{l|c|c|c|c|c|c|c|c|c|c|c|c|c|c}
\hline Variáveis & \multicolumn{10}{|c}{$\%$ de Respostas } \\
\hline & $\mathbf{0}$ & $\mathbf{1}$ & $\mathbf{2}$ & $\mathbf{3}$ & $\mathbf{4}$ & $\mathbf{5}$ & $\mathbf{6}$ & $\mathbf{7}$ & $\mathbf{8}$ & $\mathbf{9}$ & $\mathbf{1 0}$ & $\mathbf{d e ~ 0 ~ a ~ 4}$ & $\mathbf{d e} \mathbf{6} \mathbf{1 0}$ \\
\hline $\begin{array}{l}\text { Q } 11 \text { - Aplico, frequentemente, os } \\
\text { resultados das pesquisas contábeis } \\
\text { publicadas em periódicos }\end{array}$ & 20 & 3 & 10 & 10 & 4 & 21 & 8 & 5 & 10 & 3 & 6 & 47 & 32 \\
\hline $\begin{array}{l}\text { Q 22 - Os temas a seguir relacionados são } \\
\text { aqueles cujos resultados das pesquisas eu } \\
\text { mais utilizo: Contabilidade Tributária }\end{array}$ & 10 & 2 & 2 & 3 & 3 & 10 & 4 & 7 & 17 & 13 & 29 & 20 & 70 \\
\hline
\end{tabular}

Fonte: Dados da Pesquisa.

Percebe-se, na Tabela 3, o grande interesse dos respondentes em conhecer e utilizar pesquisas sobre contabilidade tributária (70\% para os níveis de 6 a 10). No entanto, em relação à variável que verifica o nível da aplicação dos resultados das pesquisas da área contábil, o maior percentual (47\%) encontra-se entre os níveis 0 e 4 , o que sinaliza a baixa aplicação dos resultados das pesquisas por parte dos respondentes.

c) ANÁLISE DOS DADOS DO FATOR 3 - “Profissional Graduado" - Os percentuais das respostas para as variáveis Q5 e Q23 são apresentados na Tabela 4.

Tabela 4: Percentuais de Posicionamentos para o Fator 3

\begin{tabular}{|c|c|c|c|c|c|c|c|c|c|c|c|c|c|}
\hline \multirow[t]{2}{*}{ Variáveis } & \multicolumn{13}{|c|}{ \% de Respostas } \\
\hline & \multicolumn{2}{|c|}{ Esc. } & \multicolumn{2}{|c|}{ Cons. } & \multicolumn{2}{|c|}{ Emp. } & & & & & & & \\
\hline \multirow[t]{2}{*}{$\begin{array}{l}\text { Q } 5 \text { - Atuo em (escritório, empresa, } \\
\text { consultoria) }\end{array}$} & \multicolumn{2}{|c|}{$32 \%$} & \multicolumn{2}{|c|}{$10 \%$} & \multicolumn{2}{|c|}{$58 \%$} & & & & & & & \\
\hline & $\mathbf{0}$ & 1 & 2 & 3 & 4 & 5 & 6 & 7 & 8 & 9 & 10 & de 0 a 4 & de 6 a 10 \\
\hline $\begin{array}{l}\text { Q } 23 \text { - Das modificações ocorridas na área } \\
\text { contábil, que tomei conhecimento, foram } \\
\text { através dos seguintes meios: graduação }\end{array}$ & 23 & 2 & 5 & 3 & 2 & 15 & 8 & 8 & 14 & 7 & 13 & 35 & 50 \\
\hline
\end{tabular}

Fonte: Dados da Pesquisa.

A maioria dos respondentes corresponde a profissionais que atuam em empresas (58\%), sendo que a atuação em escritório vem em segundo lugar com 32\%. Em relação à variável que verifica o nível de concordância de que a graduação é o meio mais utilizado para tomar conhecimento das modificações ocorridas na área contábil, o maior percentual de posicionamentos encontra-se entre os níveis 6 e $10(50 \%)$. 
d) ANÁLISE DOS DADOS DO FATOR 4 - "Dificuldade de Compreensão" - Na Tabela 5 é possível verificar os percentuais dos posicionamentos com relação às variáveis que compõem o fator 5 .

Tabela 5: Percentual de Posicionamento para o Fator 4

\begin{tabular}{l|c|c|c|c|c|c|c|c|c|c|c|c|c|c}
\hline Variáveis & \multicolumn{10}{c}{ \% de Respostas } \\
\hline & $\mathbf{0}$ & $\mathbf{1}$ & $\mathbf{2}$ & $\mathbf{3}$ & $\mathbf{4}$ & $\mathbf{5}$ & $\mathbf{6}$ & $\mathbf{7}$ & $\mathbf{8}$ & $\mathbf{9}$ & $\mathbf{1 0}$ & $\mathbf{d e} \mathbf{0}$ a 4 & de $\mathbf{6}$ a 10 \\
\hline $\begin{array}{l}\text { Q 10 - Os artigos científicos, publicados } \\
\text { em periódicos da área contabil, são de } \\
\text { difícil compreensão. }\end{array}$ & 23 & 2 & 10 & 9 & 6 & 16 & 8 & 9 & 9 & 2 & 6 & 50 & 34 \\
\hline
\end{tabular}

Fonte: Dados da Pesquisa.

$\mathrm{Na}$ análise dos resultados do fator 4, percebe-se que o maior percentual de respostas encontra-se entre os níveis 0 e 4, o que significa que grande parte dos profissionais acredita que os artigos científicos não são difíceis de compreender.

e) ANÁLISE DOS DADOS DO FATOR 7 - "Tempo de Formação" - Para evidenciar os percentuais de posicionamentos para a variável Q4, que compõem o fator 7, apresenta-se a Tabela 6.

Tabela 6: Percentuais de Posicionamentos para o Fator 7

\begin{tabular}{l|c|c|c|c}
\hline Variáveis & \multicolumn{3}{|c}{ \% de Respostas } \\
\hline Q4 - Formado a: (menos de 5 anos; entre 5 e 10; entre 10 e 15; mais de 15) & até5 & $\mathbf{5}$ a 10 & $\mathbf{1 0}$ a 15 & $\mathbf{1 5}+$ \\
\hline
\end{tabular}

Fonte: Dados da Pesquisa.

Percebe-se que $75 \%$ dos respondentes estão formados há mais de 5 anos e menos de 15 , conforme pode ser verificado na Tabela 20.

f) ANÁLISE DOS DADOS DO FATOR 8 - "Legislação" - Os percentuais dos posicionamentos para a variável Q33 que compõe o fator 8, apresentam-se na Tabela 7.

Tabela 7: Percentuais de Posicionamentos para o Fator 8

\begin{tabular}{l|c|c|c|c|c|c|c|c|c|c|c|c|c|c}
\hline Variáveis & \multicolumn{10}{|c}{ \% de Respostas } \\
\hline & $\mathbf{0}$ & $\mathbf{1}$ & $\mathbf{2}$ & $\mathbf{3}$ & $\mathbf{4}$ & $\mathbf{5}$ & $\mathbf{6}$ & $\mathbf{7}$ & $\mathbf{8}$ & $\mathbf{9}$ & $\mathbf{1 0}$ & $\mathbf{d e ~ 0} \mathbf{0} \mathbf{4}$ & $\mathbf{d e} \mathbf{6}$ a 10 \\
\hline $\begin{array}{l}\text { Q 33 - Das modificações ocorridas na área } \\
\begin{array}{l}\text { contábil, que tomei conhecimento, foram } \\
\text { através dos seguintes meios: Legislação }\end{array}\end{array}$ & 7 & 1 & 2 & 2 & 2 & 11 & 6 & 5 & 19 & 15 & 3 & 14 & 48 \\
\hline
\end{tabular}

Fonte: Dados da Pesquisa.

Por meio da Tabela 7 percebe-se que $75 \%$ dos posicionamentos se encontram entre os níveis 6 e 10. Esse resultado confirma o que os respondentes afirmaram majoritariamente de que utilizam a legislação para tomar conhecimento das modificações da área contábil.

\subsection{Resumo da Interpretação da Análise Fatorial}

Resumidamente, a interpretação da análise fatorial pode ser assim expressa:

a) $64 \%$ dos respondentes possuem pós-graduação, o que indica um bom nível de conhecimento científico; 
b) $75 \%$ dos respondentes estão formados há mais de cinco anos e menos de 15 anos;

c) dentre os respondentes, 63\% afirmam (acima do nível 5) que é frequente a leitura de periódicos da área contábil;

d) o percentual de respondentes que indicam interesse (acima do nível 5) em pesquisa e utilização do tema contabilidade gerencial corresponde a 43\%; em relação ao tema Contabilidade e Mercado de Capitais corresponde a 70\%; e em relação ao tema contabilidade tributária corresponde também a 70\%;

e) $46 \%$ dos respondentes afirmam (em nível acima de 5) que utilizam os congressos para tomar conhecimento das modificações ocorridas na área contábil; 50\% dos respondentes afirmam que utilizam a "graduação"; e 75\% afirmam que utilizam a legislação para atualização em relação aos assuntos contábeis;

f) o percentual de atuação em empresas (58\%) é maior do que a atuação em escritórios $(32 \%)$ e consultorias $(10 \%)$;

g) algumas afirmações receberam maior percentual de respostas entre os níveis 0 e 4, ou seja, representando a discordância dos respondentes. Estas afirmações sugerem as seguintes conclusões: (a) a maioria dos respondentes não mantém contato com pesquisadores da área de Contabilidade nem ao menos uma vez ao ano; (b) não participam intensamente dos congressos da área contábil; (c) pouco utilizam os meios: mestrado e periódicos impressos para tomar conhecimento das atualizações ocorridas na área contábil; (d) não têm conhecimento dos congressos que ocorrem anualmente na área contábil; (e) pouco aplicam os resultados das pesquisas realizadas na área contábil; e (f) afirmam que os resultados das pesquisas não são de difícil compreensão.

\section{CONCLUSÃO}

Este estudo objetivou examinar a interação entre a pesquisa científica e a prática da profissão contábil, realizado por meio de um instrumento de coleta dos dados (questionário), respondido por 328 contabilistas do Rio Grande do Sul.

$\mathrm{Na}$ análise fatorial foram identificados seis fatores relevantes para análise dos resultados: a) Comunicação entre contadores e pesquisadores; b) Interesse e aplicação: contabilidade tributária; c) Identificação de características; d) Profissional graduado; e) Grau de compreensão; f) Tempo de formação; e, g) Legislação.

A partir da análise dos dados, foi possível concluir que a maioria dos respondentes possui pós-graduação; a atuação em empresas é maior do que a atuação em escritórios e consultorias; a maioria afirma que é frequente a leitura de periódicos; os temas de maior interesse na opinião dos respondentes correspondem a: contabilidade e mercado de capitais, contabilidade tributária e contabilidade gerencial; e a legislação é um dos meios mais utilizados para tomar conhecimento das atualizações ocorridas na área contábil. Verificou-se também que há pouca comunicação entre profissionais e pesquisadores da área contábil e pouca participação de profissionais em eventos de cunho científico da área.

A análise fatorial revelou que é mínimo o nível de conhecimento científico e aplicação da pesquisa científica na prática da profissão. No entanto, é possível vislumbrar que há possibilidade de aproximação entre pesquisadores e profissionais, já que estes últimos expressam tal interesse, e apontam os Conselhos Regionais de Contabilidade como possíveis agentes desta aproximação.

Os temas de pesquisa evidenciados na análise fatorial como sendo de grande interesse na opinião dos contabilistas (contabilidade e mercado de capitais, contabilidade tributária e contabilidade gerencial) coincidem com os temas mais pesquisados nos congressos realizados na área contábil, assim como os estudos realizados sobre o tema, como foi apresentado no referencial teórico. Este fato representa um elemento importante para a redução de barreiras existentes entre a pesquisa e a prática contábil.

Estas barreiras correspondem, principalmente, à questão da comunicação entre academia e profissionais, onde se verificou que deve ocorrer um maior incentivo aos profissionais contabilistas no que tange à leitura de artigos e à participação em eventos científicos da área contábil, que representam passos fundamentais para a aproximação entre ambos coletivos. No entanto, é preciso que os profissionais da Contabilidade tenham o conhecimento necessário para a perfeita interpretação e o entendimento dos 
resultados das pesquisas científicas da área contábil, o que já existe na opinião dos contabilistas. Uma maior interação entre acadêmicos e profissionais da Contabilidade poderá oportunizar a elaboração de importantes projetos para a área contábil, marcada pelo engajamento de ambos, o que contribuirá para o desenvolvimento da própria área e da sociedade em geral.

A realização desse estudo oferece a oportunidade para seguir nessa linha de pesquisa, seja replicando-a em outros estados para fins de comparação dos resultados, envolvendo os demais usuários da Contabilidade e verificando de que forma as questões estruturais do sistema educacional interferem na interação entre a pesquisa e a prática contábil.

\section{REFERÊNCIAS}

ASSOCIAÇÃO NACIONAL DE PROGRAMAS DE PÓS-GRADUAÇÃO E PESQUISA EM ADMINISTRAÇÃ̃O - ANPAD. Anais... Disponível em: http://www.anpad.org.br/. Acesso em: 12/06/2009.

ASSOCIAÇÃO NACIONAL DE PROGRAMAS DE PÓS-GRADUAÇÃO EM CIÊNCIAS CONTÁBEIS - ANPCONT. Anais... Disponível em: www.anpcont.com.br. Acesso em: 12/06/2009.

BEUREN, Ilse M. Como Elaborar Trabalhos Monográficos em Contabilidade. Teoria e Prática. v.3, p.195, 2006.

CARDOSO, R. L.; MENDONÇA NETO, O. R.; RICCIO, E. L.; SAKATA, M. C. G. Pesquisa Científica em Contabilidade entre 1990 e 2003. RAE - Revista de Administração de Empresas. São Paulo. v. 44, n.3, p.100-114, jul./set., 2004.

CHIROTTO, Amanda R.; PELEIAS, Ivan R; SECRETI, João B.; SILVA, Glauco P. Evolução do Ensino da Contabilidade no Brasil: Uma Análise Histórica. Revista Contabilidade e Finanças. USP. São Paulo. n.30, p. 19 - 32, jun.2007.

COELHO, Paulo S.; SILVA, Raimundo D. S. da. Um Estudo Exploratório sobre as Metodologias Empregadas em Pesquisas na Área de Contabilidade no EnANPAD. Revista Contemporânea de Contabilidade. UFSC. Santa Catarina, v.1, n.8, p. 139-159, jul-dez., 2007.

COLLIS, Jill; HUSSEY, Roger. Pesquisa em Administração: Um guia prático para alunos de graduação e pós-graduação. 2 ed. Porto Alegre: Bookman, 2006.

CONGRESSO BRASILEIRO DE CUSTOS - CBC. Anais... Disponível em: http://cbc.edugraf.ufsc.br/. Acesso em: 14/07/2009.

CONGRESSO USP DE CONTROLADORIA E CONTABILIDADE. Anais... Disponível em: http:// www.congressousp.fipecafi.org. Acesso em: 15/07/2009.

DIAMOND, Michael. Accounting education, research and practice: after enron, where do we go? The European Accounting Review. v.14, n.2, p. 353-362, 2005.

DONOVAN, Cecil. The benefits of academic/practitioner collaboration. Accounting, Education: an international Journal. V. 14, n.4, p.445-452, Dec. 2005.

EDWARDS, K. A.; EMMANUEL, C. R. Diverging views on the boundaries of management accounting. Management Accounting Research. 1, p. 51 - 63, 1990. 
GIL, Antonio Carlos. Como elaborar projetos de pesquisa. 4. ed. São Paulo: Atlas, 2002.

HAIR JUNIOR, J. F.; ANDERSON, R. E.; TATHAM, R. L.; BLACK, W. C. Análise multivariada de dados. 5.ed. Porto Alegre: Bookman, 2009.

HAWKES, L. C; FOWLER, M.; TAN, L. M. Management Accounting Education: Is There A Gap Between Academia And Practitioner Perceptions? Massey University School Of Accountancy Discussion. Paper Series 215, June 2003.

LAFFIN, Marcos. A pesquisa nos cursos de ciências contábeis. Revista de Ciências da Administração. Florianópolis, v.2, p. 99-106, 2000.

LEISENRING, James J.; JOHNSON, L. Todd. Accouting research: on the relevance of research to practice. Accounting Horizons. Sarasota, v.8, n.4, p. 74-80, dec., 1994.

LUFT, Joan; SHIELDS, Michael. Zimmerman's contentious conjectures: describing the present and prescribing the future of empirical management accounting research. The European Accounting Review. v.11, n.4, p.795-803, 2002.

MITCHELL, Falconer. Research and practice in management accounting: improving integration and communication. The European Accounting Review. v.11, n.2, p.277-289, 2002.

MOEHRLE S. R., K. L; AYERS, Anderson, F. L.; BOLT-LEE, C. E.; DEBRECENY, R. S.; DUGAN M. T.; HOGAN, C. E.; MAHER M. W.; PLUMMER, E. The impact of academic accounting research on professional practice: An analysis by the AAA Research Impact Task Force. Accounting Horizons, 23 (4), 2009, p. 411-456.

OLIVEIRA, Marcelle C. Análise dos Periódicos Brasileiros de Contabilidade. Revista Contabilidade e Finanças. USP. São Paulo. n.29, p. 68-86, mai-ago. 2002.

OTT, Ernani. Reflexão sobre a Pesquisa em Contabilidade no Brasil. In: LOPES, Jorge; RIBEIRO FILHO, José Francisco; PEDERNEIRAS, Marcleide (Org.). Educação Contábil: Tópicos de Ensino e Pesquisa. São Paulo: Atlas, 2008. p.176 a 187.

PEREIRA, Alexandre. Guia prático de utilização do SPSS: análise de dados para ciências sociais e psicologia. 6.ed. Lisboa: Edições Silabo, 2006.

RICCIO, Edson Luiz; SAKATA, Marici Gramacho; CARASTAN, Jacira Tudora. A pesquisa contábil nas universidades brasileiras - 1962 - 1999. Universidade de São Paulo. São Paulo. 2004. Disponível em: <www.tecsi/fea/usp.br/producao $>$. Acesso em: 12 fev. 2010

THEÓPHILO, C. R; IUDÍCIBUS, S. Uma Análise Crítico-Epistemológica da Produção Científica em Contabilidade no Brasil. In: EnANPAD - Encontro da Associação Nacional de Pós Graduação e Pesquisa em Administração, 29. Anais... Brasília, 2005. 